\title{
Vertical One-and-a-Half Syndrome Due to Metastatic Spindle Cell Carcinoma of the Lung
}

\author{
Elie Côté, Jonathan A. Micieli \\ Keywords: Vertical gaze palsy, Spindle cell carcinoma, Metastases
}

doi:10.1017/cjn.2020.100

Can J Neurol Sci. 2020; 47: 685-686

A 72-year-old woman was seen in consultation for new-onset intermittent binocular vertical diplopia. Her past medical history was significant for metastatic spindle cell carcinoma of the lung with multiple brain metastases. On examination, she was found to have a supranuclear upgaze and right infraduction palsy, consistent with a vertical one-and-a-half syndrome (Figure 1). Magnetic resonance imaging (MRI) of the brain with contrast was performed, and this revealed a new enhancing mass involving the right midbrain and diencephalon, consistent with a new metastasis (Figure 2). At 5-week follow-up, she had progressed to have both complete up- and downgaze supranuclear palsies.

Spindle cell carcinoma is a very rare form of lung cancer, representing only $0.2-0.3 \%$ of all primary pulmonary cancers. ${ }^{1}$ This cancer is highly malignant with rapid progression and poor prognosis. In addition, brainstem metastases are uncommon - representing only $5-7 \%$ of brain metastases in all malignancies - and carry a poor prognosis with a median survival of less than 1 year. ${ }^{2}$ There are few existing case reports of brainstem metastases in patients with spindle cell carcinoma of the lung. ${ }^{3}$

Vertical one-and-a-half syndrome is an extremely rare finding, previously reported in patients with unilateral ischemic stroke of the meso-diencephalon. It is a result of disruption of the posterior commissure and decussating fibers to the oculomotor complex. ${ }^{4}$ Although the pathways involved in vertical gaze are incompletely understood, it is hypothesized that fibers from the contralateral rostral interstitial nucleus of medial longitudinal fasciculus (riMLF) via the posterior commissure contribute to upgaze and fibers from the ipsilateral riMLF contribute to downgaze. ${ }^{5}$ Therefore, a lesion involving the posterior commissure and ipsilateral riMLF could produce a vertical one-and-a-half syndrome.

Other horizontal one-and-a-half syndrome variants secondary to pontine metastases have been rarely described in the literature. These include reports of an isolated one-and-a-half syndrome or those in association with other cranial neuropathies. ${ }^{6-9}$ To our knowledge, this is the first case to demonstrate that vertical one-and-a-half syndrome can result from metastatic disease. Therefore, new extraocular motor deficits presenting in patients with a history of cancer should prompt urgent neuroimaging to assess for new metastatic lesions.

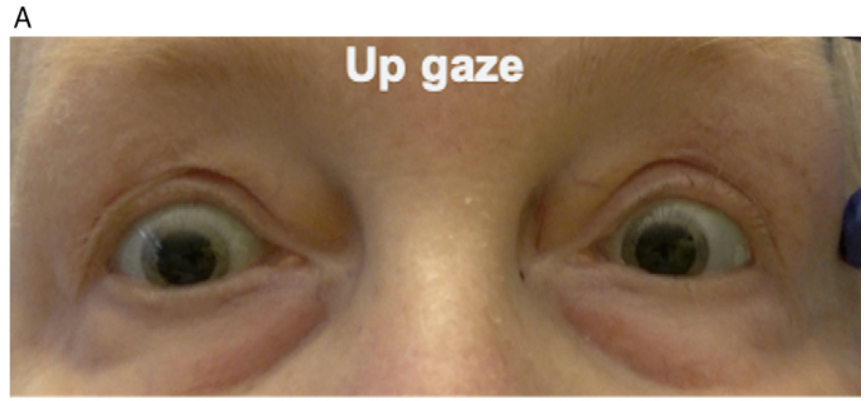

B

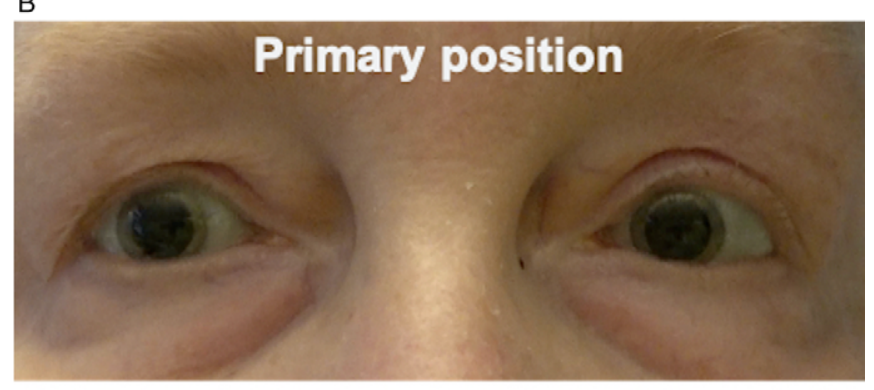

C

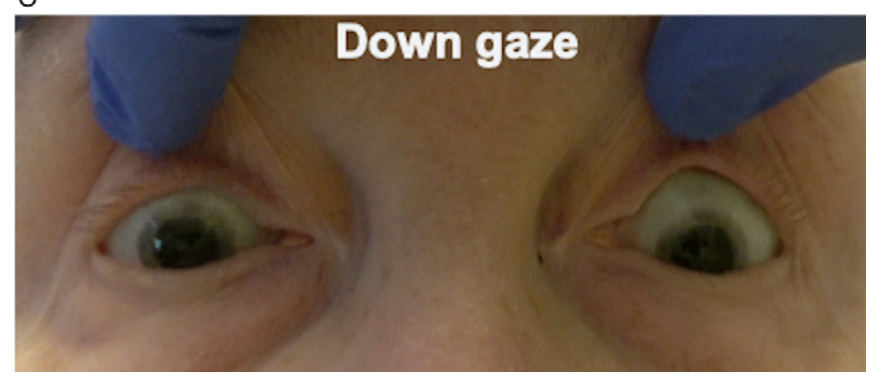

Figure 1: Assessment of ocular motility revealed an upgaze palsy $(A)$ and infraduction palsy in the right eye $(C)$. There was no deviation in primary position $(B)$. This was overcome with oculocephalic maneuvers, indicating that this was supranuclear in nature.

From the Department of Ophthalmology and Vision Sciences, University of Toronto, Toronto, Ontario, Canada (EC, JAM); and Division of Neurology, Department of Medicine, University of Toronto, Toronto, Ontario, Canada (JAM)

Received April 3, 2020. Final Revisions Submitted May 12, 2020. Date of Acceptance May 18, 2020.

Correspondence to: Dr. Jonathan A. Micieli, Kensington Vision and Research Centre, 340 College Street, Suite 501, Toronto, Ontario, Canada, M5T 3A9. Email: jmicieli@ kensingtonhealth.org 


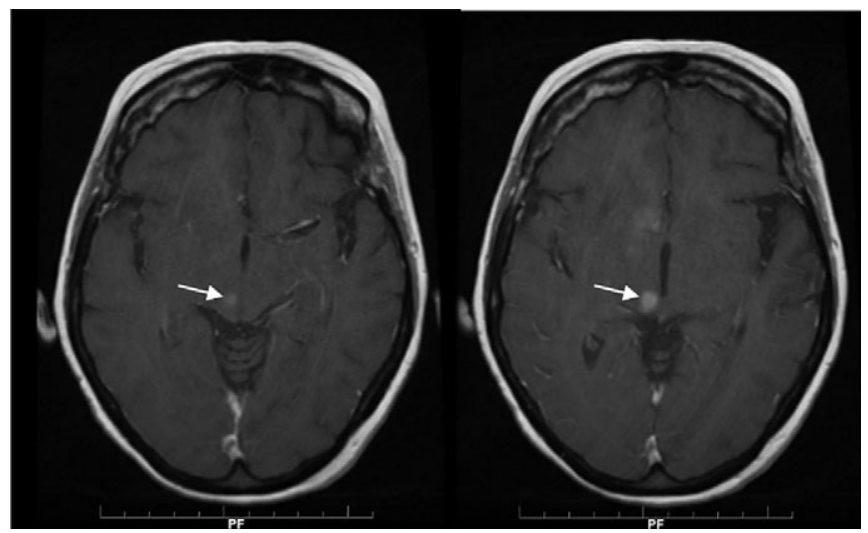

Figure 2: T1 MRI post-contrast demonstrates a metastatic lesion involving the right midbrain and diencephalon (arrow) most consistent with a metastasis.

\section{DisclosuRes}

The authors have no conflicts of interest to declare.

\section{Statement of Authorship}

EC and JAM were involved in project conception, manuscript preparation, and editing.

\section{REFERENCES}

1. Qi D-J, Liu B, Feng L, et al. Pulmonary spindle cell carcinoma with unusual morphology: a rare case report and review of the literature. Medicine (Baltimore). 2017;96(24):e7129.

2. Yoo TW, Park ES, Kwon DH, Kim CJ. Gamma knife radiosurgery for brainstem metastasis. J Korean Neurosurg Soc. 2011; 50(4):299-303.

3. Li W, Chen M, Zhao Y. Long-term survival in a patient with pulmonary spindle cell carcinoma treated with traditional Chinese medicine. Case Reports 2018;2018:bcr-2018-225989.

4. Bogousslavsky J, Regli F. Upgaze palsy and monocular paresis of downward gaze from ipsilateral thalamo-mesencephalic infarction: a vertical "one-and-a-half" syndrome. J Neurol. 1984; 231(1):43-5.

5. Sato K, Takahashi Y, Matsumoto N, et al. Rare valiant vertical oneand-a-half syndrome without ipsilateral upward gaze palsy in a patient with thalamomesencephalic stroke. Neurol Clin Neurosci. 2018;6(5):133-5.

6. Jackel RA, Gittinger JW, Smith TW, Passarelli CB. Metastatic adenocarcinoma presenting as a one-and-a-half syndrome. Clinical, radiological, and pathological correlations. J Clin Neuroophthalmol. 1986;6(2):116-9.

7. Crisostomo EA. One-and-a-half syndrome in a patient with metastatic breast disease. J Clin Neuroophthalmol. 1985;5(4):270-2.

8. Patil M, Ganger A, Sharma S, Saxena R. Metastatic renal cell carcinoma presenting as one-and-a-half syndrome. Indian $\mathbf{J}$ Ophthalmol. 2017;65(9):895-7.

9. Choi S-M, Kim TG, Chung J, et al. Sixteen-and-a-half syndrome with metastatic pons tumor: a case report. Medicine (Baltimore). 2019;98(47):e18006. 